\title{
MANOEL BOMFIM E AS ESPECIFICIDADES DA FORMAÇÃO BRASILEIRA: A CONQUISTA DO TERRITÓRIO COMO ELEMENTO DEFINIDOR DA IDENTIDADE NACIONAL
}

\author{
MANOEL BOMFIM AND THE SPECIFICITIES OF THE BRAZILIAN'S \\ FORMATION: THE CONQUEST OF TERRITORY AS A DEFINING \\ ELEMENT OF NATIONAL IDENTITY
}

DOI: http://dx.doi.org/10.15448/2178-3748.2018.1.24808

\author{
Luiz Carlos Bento \\ Doutor em História (UFG) - Professor adjunto na UFMS \\ uizc.bento@yahoo.com.br
}

\begin{abstract}
RESUMO: Ao longo deste texto, buscamos sistematizar o entendimento de Manoel Bomfim apresentado em seus ensaios América Latina: Males de Origem (1905) e O Brasil na América: caracterização da formação brasileira (1929) a respeito do processo de formação do Brasil e das demais nações neo-ibéricas, buscando realçar sua crítica ao caráter violento e exploratório desse processo que, segundo o pensador sergipano, era oriundo do sistema colonial e de seu aparato funcional, com especial ênfase para as influências negativas da escravidão. Esse enfoque na ocupação dos espaços e na inclusão dos indivíduos evidencia a importância atribuída por Manoel Bomfim à conquista e à ocupação do território como elemento definidor das especificidades nacionais, tema que procuramos explorar por meio de uma reflexão sobre os dois ensaios supracitados.
\end{abstract}

PALAVRAS-CHAVE: Formação. Identidade. Nação.

ABSTRACT: Throughout this text, we systematize the understanding of Manoel Bomfim presented in their essays América Latina: Males de Origem (1905) and O Brasil na América: caracterização da formação brasileira (1929) regarding the process of Brazil's formation and other neo-iberian nations, seeking to highlight its criticism of the violent and exploratory character of this process which, according the Sergipe's thinker, was resulting from the colonial system and its functional apparatus, with special emphasis on the negative influences of slavery. This focus on occupation of spaces and the inclusion of individuals shows the importance attributed by Manoel Bomfim to the conquest and occupation of territory as a definer element of national specificities, which we seek to explore through a reflection about the two aforementioned essays.

KEYWORDS: Formation. Identity. Nation.

O sergipano Manoel Bomfim ingressou na Faculdade de Medicina da Bahia em 1886, mas finalizou seus estudos na capital do Império em 1888. Dessa forma, sua biografia se assemelha a de outros intelectuais provincianos que migraram para o Rio de Janeiro e conseguiram fazer carreiras como escritores, jornalistas e professores. Uma especificidade biográfica de Bomfim é que, por ter nascido em 1868, ele pôde gozar de uma oportunidade rara e acessível a poucos homens, pois conseguiu acompanhar já com certa maturidade os principais acontecimentos sociais e políticos que marcaram o processo de transição da 
Monarquia à República no Brasil. Desta forma, o projeto nacional presente em sua obra se situa entre a crítica à Monarquia, as teses raciais e o desejo de reformas modernizadoras capazes de redefinir o sentido da nacionalidade na aurora da república brasileira.

O conjunto de questões abordadas por Bomfim nos dois ensaios analisados neste texto estão longe de se constituir em novidade no campo intelectual brasileiro. Assim, o que o diferencia substancialmente de outros autores do período não são as suas temáticas, mas, sim, sua leitura dissonante de uma tradição histórica assentada nos valores monárquicos, da qual procurou se afastar por meio de uma crítica sistemática de suas referências teóricas, metodológicas e ideológicas.

Esse aspecto da obra de Bomfim levou alguns de seus primeiros intérpretes, entre os quais Dante Moreira Leite (1992), Tomas Skidmore (2012) e Darcy Ribeiro (1993), a considerá-lo, de forma apressada, "um homem à frente do seu tempo". Tal interpretação, além de ser descaracterizada por seu sentido a-histórico, deve ser compreendida pela incapacidade de situar Bomfim no interior da tradição a qual ele critica, mas da qual ele não pode ser desvinculado sem, com isso, se perder o sentido histórico da leitura de seu próprio tempo e de sua visão histórica de mundo, que são chaves fundamentais para compreendermos as suas obras como representações históricas de uma dada realidade historicamente constituída.

O processo de formação da nacionalidade brasileira é narrado por Bomfim partindo de um quadro geral, no qual se vislumbram características comuns entre o Brasil e as demais nações latino-americanas. Ao longo de seu texto, as nações que se formaram nessa parte do globo são apresentadas como personagens que protagonizaram de formas diferentes uma mesma tragédia, que seria a experiência da colonização empreendida pelos países ibéricos.

Bomfim não enxergava heranças positivas nesse processo; pelo contrário, sua narrativa enfatiza a dinâmica violenta, depredadora e espoliativa dessa empresa sob a qual nasceram às nações neo-ibéricas e em relação à quais elas devem ser pensadas para que se compreendam os verdadeiros males da formação social dessas nacionalidades. Segundo sua interpretação, essas nações apresentaram-se à modernidade, desprovidas de condições mínimas para se adequarem às necessidades dos novos tempos; contudo, segundo ele, tal situação não derivava de condições de meio ou raça, mas, sim, de seus antecedentes históricos. Bomfim busca demonstrar que a escolha por implantar e manter as estruturas básicas do colonialismo foi uma opção civilizacional equivocada, que trouxe problemas para o desenvolvimento futuro dessas nações.

Bomfim faz, em seu ensaio histórico, um escrutínio crítico da experiência colonial ibérica. Em seu estudo, ele reconhece as distinções entre a colonização empreendida pelas 
duas nações peninsulares na América, bem como da colonização ibérica em relação à empreendida pelos ingleses na América do Norte. Contudo, mesmo reconhecendo certas distinções entre o modelo espanhol e português de colonização, seu intuito é demonstrar que existe um complexo de características gerais que são norteadoras da empresa colonial ibérica e que estão presente em toda a América do Sul.

Essas características gerais da colonização ibérica estavam ajustadas às práticas culturais empreendidas secularmente pelas nações colonizadoras e que foram transplantadas para a América por meio de um processo histórico que Bomfim narra como uma evolução do "parasitismo heroico". Bomfim usa essa expressão para narrar a formação cultural do pensamento ibérico, que, unindo necessidades de expansão da fé cristã com as necessidades de ampliação de riquezas econômicas, por meio da expansão mercantilista depois da expulsão dos árabes da península, gerou entre os ibéricos um sentimento e a necessidade de "conquistar o mundo".

Esse complexo cultural marcado pelo espírito aventureiro levou espanhóis e portugueses à descoberta e conquista da América. Bomfim narra esse processo como eminentemente trágico e orientado primordialmente pela cobiça e pela violência:

Os portugueses cortavam os pés e as mãos das mulheres para arrancarlhes os brincos e braceletes - os espanhóis arrasaram um mundo para colher alguns sacos de ouro. Trinta anos depois de pisarem os espanhóis no continente americano, ninguém que visitasse as paragens do México ou do Peru seria capaz de desconfiar, sequer, que ali existiram dois impérios adiantados, fortes, populosos, encerrando um mundo de tradições. Tudo desaparecera (BOMFIM, 2005, p. 107).

Como seu objetivo inicial é descaracterizar estruturalmente a experiência colonial, seu texto não contém elogios para os colonizadores brancos ou para o ideal de civilização que eles supostamente defendiam; seu olhar busca a alteridade, não apenas para reconhecer-lhe a diferença e o direito de existir no mundo, mas, sobretudo, para denunciar seu processo de vitimização. Seu esforço discursivo é o de tentar dar voz e visibilidade aos excluídos da história da colonização, realçando o que ele entendia como as crueldades desse processo.

Em América Latina: Males de Origem (1905), Bomfim não seleciona adjetivos suaves para descrever esse processo; pelo contrário, seu estilo textual busca chocar, causar impacto pelo realce da violência empreendida no processo de formação histórica dessas nações. Segundo suas palavras, os colonizadores:

[m]ataram, trucidaram, exterminaram, destruíram, incendiaram, arrasaram tudo o que havia. Aquele mundo, onde vinte anos atrás existiam duas 
civilizações originais, exuberantes, ricas de povos, tradições e monumentos - aquele mundo era agora um acampamento desordenado, restos de ruínas, cinzas e cadáveres (BOMFIM, 2005, p. 111).

Como podemos observar nessa passagem, o processo de conquista da América para o intelectual sergipano nada teve de paradisíaco; pelo contrário, foi um processo extremamente traumático que geraria profundas sequelas nas sociedades herdeiras dessa história. De forma bastante sintética, podemos dizer que a intenção de Bomfim é caracterizar o processo de formação dessas novas nacionalidades como seriamente marcadas pela violência e pelo horror. Guardadas as devidas proporções que toda comparação sugere, existe certa proximidade nas descrições das violências do colonialismo feitas por Bomfim, em algumas passagens de América Latina, com a narrativa de Joseph Conrad em O coração das trevas (1902); embora as obras abordem cenários diferentes sobre pontos de vistas teóricos distintos, o pano de fundo das duas narrativas apresenta o fracasso do colonialismo e as atrocidades praticadas em nome de um projeto de civilização e de progresso. Dessa perspectiva, emerge a sua defesa da necessidade de rompimento em relação a esse passado que, ao longo de seu ensaio, Bomfim demonstra como o caminho sempre sonhado, mas nunca alcançado pela tradição brasileira.

Segundo Bomfim, os primeiros anos da colonização foram marcados pela conquista e depredação violenta das riquezas naturais do novo mundo. Com a diminuição dessas riquezas, houve um processo de adaptação dos colonizadores, dando início à sedentarização por meio da implantação de uma economia baseada no latifúndio agroexportador movido pela escravidão do índio e, posteriormente, do negro, fatores que manchariam o desenvolvimento das novas nacionalidades na América Latina, visto que essas práticas deixariam marcas profundas e indeléveis na cultura dessas sociedades. Nas palavras de Bomfim, no desenvolvimento histórico das nações ibéricas na América:

Elas viveram sempre, desde o primeiro momento, de uma vida parasitária; como se educaram nessas depredações; como se viciaram e se perverteram; como de guerreiras por necessidade, passaram a aventureiras por educação, e como de aventureiras e depredadoras se fizeram parasitas sedentárias (BOMFIM, 2005, p. 116-117).

Como podemos perceber nessa citação, Bomfim estabelece um padrão evolutivo para o desenvolvimento do "parasitismo colonial". Por meio dessa metáfora, ele apresenta uma leitura histórica da formação da sociedade colonial, cuja lógica que se impôs como modelo para a estruturação dessa sociedade era a exploração do trabalho do escravo, situado na hierarquia dessa sociedade como um pária, mas que sustentava todo o regime, pois era o único 
que produzia, garantindo a manutenção de todo o sistema. Bomfim conceitua, assim, a colonização ibérica como um regime de parasitismo total, em que todas as instituições na estrutura do sistema alimentavam-se das riquezas extraídas da colônia. Segundo ele, todas as classes encontravam-se incorporadas na prática do parasitismo:

O Estado era parasita das colônias; a Igreja parasita direta das colônias, e parasita do Estado. Com a nobreza sucedia a mesma coisa: ou parasitava sobre o trabalho do escravo, nas colônias, ou parasitava nas sinecuras e pensões. A burguesia parasitava os monopólios, no tráfico do negro, no comércio privilegiado. A plebe parasitava nos adros das igrejas ou nos pátios dos fidalgos (BOMFIM, 2005, p. 116-117).

Olhando para o passado brasileiro e latino-americano de uma forma geral, Bomfim narra uma história que se inicia com a educação agressiva dos povos ibéricos e que irá se converter em um processo de expansão depredadora no período mercantilista, culminando na constituição de uma sociedade estagnada por um processo de fixação sedentária. Essa seria, para Bomfim, a essência da sociedade colonial: uma formação social profundamente antagônica na qual predominavam duas classes muito distintas "os escravos índios e pretos, e as várias sortes de instrumentos que a metrópole atirava para lá, a fim de apropriar-se do trabalho desses escravos" (BOMFIM, 2005, p. 131). Seria da oposição dessas duas classes que emergiria, no processo de luta dos colonos contra a dominação metropolitana, uma terceira, que Bomfim irá identificar como constituidora de uma legítima tradição nacional, formada por "negros e índios tapuios principalmente - que defenderam Pernambuco, e o reconquistaram para Portugal” (BOMFIM, 2005, p. 139).

Bomfim trava, em seu ensaio, uma verdadeira cruzada para demonstrar o teor negativo e moralmente indesejável das práticas sociais na vida colonial. Seu objetivo é expor o peso histórico do colonialismo na formação da América Latina, demonstrando que o processo de coisificação do negro e do índio trouxe prejuízos morais inegáveis para as sociedades futuras, visto que suas tradições nacionais irão se formar numa relação direta de afirmação e negação em relação às práticas do colonialismo. Segundo Bomfim, os colonos impunham aos índios e aos negros situações que não seria lícito impor a nenhuma espécie de gado. Seu objetivo era demonstrar o caráter moralmente pernicioso da escravidão, vista por ele como:

[a]bjeção moral definitiva, a perversidade e a desumanidade permanentes: gerações e gerações de homens que viveram a martirizar, a devorar gerações de índios e de negros escravos - pela fome, açoite, a fadiga... Não havia nada de humano nas relações de senhor e escravo. Arrancado à selva nativa, abandonado aqui à ganância implacável do colono, o pobre africano só tinha um meio de libertar-se: a morte (BOMFIM, 2005, p. 149). 
Como podemos perceber nesse trecho, Bomfim atribui ao sistema colonial e ao escravismo a responsabilidade pelo atraso geral das sociedades latino-americanas. Segundo suas próprias palavras, essas sociedades "são em geral arquivos de instituições e costumes arcaicos com etiquetas modernas; um glossário moderno designando um mundo obsoleto" (BOMFIM, 2005, p. 185). Sua intenção é colocar em xeque as teorias deterministas, apontando para o sentido histórico desses problemas, e, portanto, passíveis de serem corrigidos. Sua leitura da escravidão é crítica e taxativa; para ele, tal prática foi responsável pela “abjeção moral, a degradação do trabalho, o embrutecimento e o aniquilamento do trabalhador" (BOMFIM, 2005, p. 150), gerando males duradouros e extensos na formação cultural dessas novas nacionalidades.

Além de contribuir negativamente para a psicologia social dessas novas sociedades, o sistema colonial ibérico também trouxe prejuízos econômicos sensíveis. Isso porque, se somando os maus efeitos da escravidão com as consequências negativas dos monopólios comerciais instituídos sobre o comércio entre metrópole e colônia - que levaram as proibições formais ao desenvolvimento de indústrias manufatureiras, restringindo a atividade econômica a plantation e a mineração -, constitui-se um modelo de exploração econômica profundamente extrativista, responsável pela retirada ostensiva da riqueza da região, deixando essas nações profundamente pobres no momento de sua ruptura com a lógica colonial. No pensamento de Bomfim, a riqueza da América Latina fomentou o desenvolvimento europeu à custa do seu empobrecimento e amesquinhamento econômico e cultural.

Partindo desse pressuposto, Bomfim entende que a contribuição econômica e cultural do sistema colonial para as novas nacionalidades foi negativa. Seria como se "dezenas de gerações de milhões de índios e negros não houvessem morrido a trabalhar, sobre um solo fertilíssimo, semeado de minas preciosíssimas" (BOMFIM, 2005, p. 156), pois para o intelectual sergipano, desse processo que durou mais de trezentos anos só restaram, além das heranças negativas, sobras envelhecidas de "engenhocas, casebres, igrejas, santos, monjolos, e almanjarras, bois minúsculos, de mais chifres do que carnes, e cavalos anões e ossudos" (BOMFIM, 2005, p. 156), em razão de as riquezas extraídas do continente durante todo esse período não terem se fixado na América, sendo trasladada para o Velho Mundo. Bastaria que uma ínfima parte das riquezas exploradas ao índio e aos escravos tivesse sido investida na melhoria das condições da região para que o presente e o futuro dessas nações fossem outro.

Ao longo de seu ensaio, Bomfim objetiva demonstrar que o futuro dessas novas nacionalidades passaria necessariamente por um rompimento radical com as heranças desse 
passado. As únicas coisas que ele entendia que deveriam ser resguardadas desse período eram "a sociabilidade afetiva, natural entre as populações, e os sentimentos de hombridade e independência nacional característicos destes povos” (BOMFIM, 2005, p. 179).

Com isso, seu texto apresenta uma perspectiva de interpretação histórica que é inovadora e singular, visto que rompe com a lógica da historiografia do período, a qual estava preocupada em pensar o nacional com base em uma relação de continuidade com a herança colonial.

Bomfim entende que, desse passado colonial, o único aspecto a ser valorizado era o esforço de alguns colonos em alguns momentos da vida colonial (revoltas nativistas) em se rebelarem contra a dominação metropolitana, buscando afirmar seus interesses em oposição à lógica do sistema. Ou seja, em América Latina, o intelectual sergipano pondera que a única experiência histórica do passado colonial que serviria para as nacionalidades latinoamericanas seriam alguns esforços duramente sufocados de negação do colonialismo ibérico. Para ele, tais esforços eram representativos dessas novas tradições que se formaram em meio a movimentos de reação e conservação do colonialismo.

Bomfim identifica, assim, em seu texto, duas tradições: uma dominante, que visava à conservação da lógica colonial; e outra, marginal, que era reativa em relação ao colonialismo. Para ele, a história desses povos deve ser narrada com base nessas duas tendências, compondo um movimento dialético entre conservação e mudança que permeia sua formação.

O espírito conservador, que ele identifica como uma tendência da elite, justifica-se pelo desejo de manutenção dos privilégios classistas constituídos ao longo do colonialismo, que mantém uma relação com o passado a fim de legitimar o status quo adquirido. Bomfim esforça-se para demonstrar a irracionalidade desse pensamento, uma vez que, para ele, não havia nada de positivo a se conservar desse passado, a não ser a manutenção de privilégios e egoísmos individuais. Para Bomfim, o conservadorismo era nada mais que o colonizado pensando pela lógica do colonizador; era a assimilação de um padrão dominante de cultura justificada por interesses individuais, classistas e nada patrióticos.

Em seu discurso, Bomfim tem o intuito de dar visibilidade à outra tradição, a marginalizada na lógica do sistema, e que, segundo ele, atendia às necessidades reais desses povos que se formaram pela experiência colonial na América, que desenvolveram um modo de vida próprio e gradativamente foram se opondo à lógica colonial. Para Bomfim, essa tradição nacional associada às necessidades da terra e às condições de vida das populações sertanejas representavam a essência das nações latino-americanas. 


\section{MANOEL BOMFIM E A CARACTERIZAÇÃO DA FORMAÇÃO BRASILEIRA EM O BRASIL NA AMÉRICA}

Quase vinte anos após a publicação de América Latina, Bomfim dá início à elaboração de uma trilogia historiográfica para pensar a formação histórica da nação brasileira, cuja primeira obra é $O$ Brasil na América: caracterização da formação brasileira ${ }^{1}$. Os motivos que conduzem Bomfim a esse projeto são múltiplos e, como envolvem questões subjetivas, são difíceis de serem identificados com clareza. Contudo, entendemos que uma de suas grandes motivações era estabelecer uma crítica ao processo de consolidação de uma memória histórica nacional com base nas práticas comemorativas desenvolvidas pelo IHGB, instituição que buscava produzir uma síntese conservadora da história nacional - garantindo um lugar para a tradição imperial na história produzida pela República na década de 1920.

Diante desse esforço do IHGB para consolidar um entendimento histórico do Brasil como resultado da ação do colonizador branco, português e católico, que institui a independência como o processo fundador da nacionalidade conquistada pela presença e ação centralizadora do estado bragantino, o intelectual sergipano irá propor outra história, construída quase que de forma oposta à versão dominante na historiografia. Nela, são o Estado e a elite que são representados como bárbaros e traidores de um povo forte, heroico, bom e plenamente apto ao progresso e à civilização. Nosso intuito não é refletir sobre o grau de verossimilhança histórica dessas interpretações, senão apenas pensar as possibilidades de sentido que cada uma delas encerra para a escrita da história do Brasil, buscando identificar os interesses sociais que as orientam.

No projeto historiográfico de Bomfim, o Brasil é apresentado como uma nação constituída desde o período colonial por um processo dialético de prolongamento e, ao mesmo tempo, de negação da metrópole, atingindo a sua idade de ouro no século XVII. A primeira obra de sua trilogia distingue-se, em muitos aspectos, em relação a sua obra inaugural. Nela sua crítica ao colonialismo é bem menos veemente que em América Latina, bem como sua leitura do papel do português na formação histórica da nação brasileira, o que torna $O$ Brasil na América a sua obra menos antilusitana.

Na obra em questão, seu objetivo é pensar a especificidade da formação brasileira em relação aos demais países latino-americanos; contudo, ao contrário do que havia proposto em América Latina, sua ênfase não está mais na análise dos processos análogos do colonialismo

\footnotetext{
${ }^{1}$ Segundo informações fornecidas pelo próprio Manoel Bomfim em prefácios de suas obras, o primeiro volume de sua trilogia histórica foi escrito em julho de 1925, encaminhado para impressão em 1927, mas publicado apenas em 1929.
} 
ibérico que legariam heranças históricas comuns às novas nacionalidades americanas, mas, sim, na singularidade da formação brasileira, estabelecendo particularidades e diferenças.

Nas primeiras páginas da obra, o termo "América Latina” é colocado em xeque, sendo apresentado como um estratagema ideológico que mais complica do que esclarece, pois refere-se, de forma generalizada, em um mesmo conceito, a nacionalidades que, embora tivessem passado por experiências históricas até certo ponto análogas ao colonialismo ibérico, eram plenamente distintas. Em sua perspectiva, o termo serviria apenas como indicativo de localização geográfica para essas novas nacionalidades, não podendo ser elevado ao postulado de uma identidade geral que fosse comum aos países dessa região, pois, para ele, existiam mais diferenças entre os países neo-ibéricos do que entre as metrópoles colonizadoras.

Prefaciando a segunda edição da terceira obra da trilogia historiográfica de Bomfim, Ronaldo Conde Aguiar (1996) vai chamar atenção para o fato de que ele tinha consciência de que o uso generalizado do termo América Latina não passava de um "ardil ideológico das elites, que, associadas aos interesses neocoloniais das ex-metrópoles europeias, procuravam igualar nações heterogêneas, de modo a amesquinhá-las como unidades nacionais soberanas". (AGUIAR, 1996, p. 25).

A tese de Bomfim sustentada ao longo da obra é a de que o processo de constituição da identidade nacional brasileira é único em toda a América. Tal processo é apresentado como uma verdadeira epopeia recheada de heroísmos, pois, para ele, uma identidade nacional havia surgido nos primeiros séculos de colonização em meio a lutas pela defesa do território frente a franceses, ingleses e, sobretudo, holandeses. Segundo suas palavras, o Brasil foi à única colônia a:

[r]esistir com seus próprios recursos a invasores estrangeiros; foi a única a crescer por seus próprios meios; foi a primeira a apresentar uma nova sociedade, saída da colonização, mas distinta dos colonos propriamente ditos (BOMFIM, 1997, p. 35).

Seu interesse é pensar o processo de caldeamento, não só de raças, mas também das tradições que formaram o Brasil colonial, apresentando os agentes sociais que teriam contribuído para a formação de uma identidade nacional, precoce e única em toda a América. As teses e argumentações apresentadas na obra dialogam com o contexto intelectual dos anos 1920 e são movidas pelo interesse de pensar a questão nacional, fato que leva Maria Thétis Nunes (1997) a considerar Bomfim e a obra O Brasil na América pioneiros de uma ideologia nacional que mergulha profundamente no passado colonial brasileiro e hispano-americano, 
pinçando similaridades e distinções do colonialismo e apontando marcas sociais, econômicas e políticas que permaneceram de forma estrutural nessas novas sociedades como heranças desse processo.

Para caracterizar a formação brasileira e apresentar os seus agentes históricos, Bomfim abranda a sua leitura crítica em relação ao colonialismo português, esforçando-se, ao longo da primeira parte da obra, para realçar os aspectos positivos da colonização portuguesa na América. Seu texto representa Portugal como a primeira nacionalidade moderna, com identidade nacional plenamente constituída antes mesmo da expansão marítima. Seu intuito é apresentar a conquista do Atlântico como um feito unicamente português, uma nação eminentemente marítima em oposição à Espanha, que teria se beneficiado das descobertas e feitos lusitanos. Para Bomfim; "Portugal dominou os mares, e arrancou-lhes os últimos segredos, para dar à civilização a plena posse do planeta” (BOMFIM, 1997, p. 46).

Embora seja uma leitura distinta, essa não é uma novidade, pois Bomfim retoma uma analogia presente em América Latina quando analisa a passagem do "parasitismo heroico" para o "parasitismo sedentário". Seu objetivo é postular a importância do protagonismo ibérico nos séculos XV e XVI como forma de justificar sua tese de que a primeira experiência de colonização do Brasil, caracterizada pelo esforço de implantação de um sistema de exploração agrícola, guarda as marcas desse período heroico da história portuguesa, cujos aspectos positivos teriam sido transferidos para cá pelo sistema das capitanias hereditárias.

Bomfim busca contrastar a experiência colonial lusitana da castelhana, entendendo a primeira como caracterizada pela formação de uma vida agrícola que obriga a fixação do homem à terra, criando vínculos identitários com o meio e obrigando um processo de ocupação e povoação regular para a extração de riquezas que não eram imediatas, em contraposição à segunda, que, pelo acesso direto a grandes riquezas por meio da dominação de astecas e incas, constituíram-se como "pioneiros da fortuna rápida" (BOMFIM, 1997, p. 85). A não existência de "riquezas fáceis" e a necessidade de efetivação do domínio português sobre suas terras na América culminaram no desenvolvimento do modelo das capitanias que, em determinados casos, foi uma experiência desastrosa, mas que, na perspectiva de Bomfim, não chegou a ser uma catástrofe total, pois desse modelo surgiram os dois núcleos de povoamento que foram essenciais para a formação da nacionalidade brasileira, que são Pernambuco e São Paulo.

Segundo essa interpretação, foi a partir do vínculo desses primeiros colonos com a terra que nasceu o "espírito de intransigente defesa do território, que se tornou tradição brasileira" (BOMFIM, 1997, p. 88), e que garantiu a posse das terras para Portugal influindo 
diretamente sobre a história das outras nações europeias e também sobre as futuras nacionalidades latino-americanas, pois a defesa, ocupação e expansão das terras portuguesas previstas pelo tratado de Tordesilhas modelaram geopoliticamente a América.

Bomfim narra esse processo como um feito que atinge proporções históricas inigualáveis, apresentando um mito fundador para a nação brasileira, em que, ao mesmo tempo em que se constitui uma identidade nacional distinta em relação à antiga metrópole e também pioneira em relação às demais nacionalidades americanas, cria-se a imagem dessa nova tradição nacional como vigorosa e "nascida em berço esplêndido". Isso porque sua apresentação ao mundo faz-se por meio de um exemplo de força e resistência que foi capaz de superar as nações mais poderosas da época (França, Inglaterra e Holanda).

Ao analisar essa obra, Terezinha Alves de Oliva (1998) busca demonstrar a existência de um forte viés geográfico no pensamento bomfiniano, visto que "ocupação, desbravamento, defesa, constituíram atos fundantes de uma pátria que se reconhece como tal à medida que aprofunda e revela o conhecimento do seu espaço" (OLIVA, 1998, p. 83). Como pode ser percebido, Bomfim pensa o nacionalismo como a identificação do indivíduo com a terra, fator preponderante capaz de conduzir os indivíduos à solidariedade coletiva e à confiança da necessidade da liberdade e, posteriormente, da independência.

Esse esforço de releitura histórica é empreendido pela análise da obra de cronistas do período colonial, como Robert Southey (1774-1843) e Frei Vicente de Salvador (1564-1636), a quem o primeiro volume da trilogia é dedicado. Além do suporte dos autores supracitados, Bomfim faz uso de textos de cronistas franceses, como Jean de Lery (1536-1613) e André Trevet (1502-1590), e de vários documentos e textos publicados pela Revista do IHGB, inclusive de Von Martius. Todavia, a grande influência historiográfica que exerce uma função orientadora para o desenvolvimento das hipóteses de Bomfim é a obra de Capistrano de Abreu (1853-1927).

Em linhas gerais, $O$ Brasil na América estrutura-se sobre um procedimento analítico de rever algumas das teses de Varnhagen sobre o período colonial, tendo como referência teórica a obra historiográfica de Capistrano de Abreu e, como suporte documental, a obra de Frei Vicente de Salvador, redescoberta e publicada por Capistrano. A obra tem interlocutores externos claros; por um lado, dialoga criticamente com a perspectiva historiográfica do IHGB e, por outro, com os defensores das teorias raciais, cujo expoente mais significativo no período era Oliveira Viana, no contexto brasileiro, e Garcia Calderón (1834-1905), José Ingenieros (1877-1925) e Carlos Octávio Bunge (1875-1918), no contexto latino-americano. 
Partindo da leitura de Varnhagen, Oliva (1998) aponta que Bomfim constrói um argumento de que a historiografia corrente minimiza a importância e a força da presença francesa no Brasil. Segundo a autora, seu intuito é demonstrar, por meio de um diálogo com a historiografia, que o Brasil teve de ser reconquistado do domínio francês que se fazia ostensivamente presente nos primeiros anos da colonização e o "quanto [era] mal contada a história do Brasil a respeito dos ataques franceses" (BOMFIM, 1997, p. 94) pois, no entendimento comum, os franceses fizeram apenas duas grandes investidas sobre as terras portuguesas: no Rio de Janeiro e no Maranhão. Entretanto, para Bomfim, a realidade era bem outra, sendo a presença francesa uma realidade constante que antecedeu a própria empresa colonial portuguesa. Dessa forma, as "nossas histórias correntes, falhas em tanta coisa, o são, principalmente, na pouca importância que dão às populações naturais quanto à formação do Brasil” (BOMFIM, 1997, p. 94).

Para Bomfim, o indígena foi um fator fundamental para a construção do Brasil, perdendo em grau de importância apenas para o português, porque a este coube a direção de todo o processo. Em América Latina, o contato entre colonizadores e indígenas é descrito por Bomfim de forma profundamente antirromântica, como uma experiência caracterizada pela direção violenta e desumana por parte dos colonizadores. Já em O Brasil na América esse contato é apresentado de forma bastante idealizada, quase bucólica, visando realçar os aspectos positivos desse processo. $\mathrm{O}$ índio, presente especificamente nessa obra de Bomfim, conserva fortes traços do nativo idealizado pelo Romantismo brasileiro, como elemento portador da identidade nacional, tanto que, na caracterização dos indígenas, além dos já citados Robert Southey e Frei Vicente de Salvador, é patente a influência da interpretação produzida por Gonçalves Dias em relação aos autóctones.

Essa aproximação do pensamento de Bomfim com as teses do Romantismo brasileiro fica mais evidente na segunda obra da trilogia, mais especificamente no capítulo intitulado " $\mathrm{O}$ patriotismo brasileiro", em que o autor irá destacar a importância dos poetas e escritores românticos como: Castro Alves (1847-1871), Fagundes Varella (1841-1875), Álvares de Azevedo (1831-1852), José de Alencar (1829-1877) e Gonçalves Dias (1823-1864), apresentados por Bomfim como os melhores representantes do país no mundo das letras. No último livro da série, Bomfim vai apresentar esses pensadores como os únicos representantes de um pensamento considerado por ele como genuinamente brasileiro.

Em síntese, dessa primeira sociedade colonial descrita por Bomfim, saltam algumas características que configuram a essência desse primeiro Brasil idealizado pelo intelectual sergipano, em que o português "plástico, adaptável e assimilador, traquejado no contato com

Oficina do Historiador, Porto Alegre, EDIPUCRS, v. 11, n. 1, jan./jun. 2018, 
populações exóticas" (BOMFIM, 1997, p. 100), juntou-se francamente em sangue e costumes aos indígenas, fazendo da mistura de raças e tradições a essência da cultura brasileira em formação. Nas palavras de Bomfim, o português, associando-se aos índios, "explorou-os quanto pôde, maltratou-os algumas vezes, mas foi infinitamente mais humano do que qualquer dos outros colonizadores, inclusive os franceses" (BOMFIM, 1997, p. 108) Assim, na representação de Bomfim, o português seria o mais humano dos colonizadores por causa do seu caráter "plástico e assimilador".

Nota-se que existe grande similaridade entre a idealização feita em relação ao cruzamento entre colonizadores e indígenas por Bomfim em 1925 e a idealização posteriormente tornada clássica por Gilberto Freyre (1933), que reproduz a mesma lógica de pensamento em outro espaço social e temporal, definido pelo encontro entre colonos e negros, o eixo norteador de seu pensamento. Nos dois autores, a grande questão colocada é a compreensão positiva da miscigenação como característica inerente à formação brasileira, que deveria ser reconhecida e realçada como um elemento constituinte da identidade nacional. Ambos os autores, com destaque para o pioneirismo de Bomfim, pensam o sentido positivo dos cruzamentos raciais e culturais para a constituição de um modo de ser nacional.

Bomfim defende a ideia de que o colono português, por causa de seu caráter plástico e adaptável, reconheceu, logo de início, que seria indispensável amparar-se nos indígenas para tirar deles todo o auxílio possível para a conquista do território e concorria positivamente para isso a atitude despretensiosa dos colonos portugueses, que não eram soberbos como os espanhóis, nem tinham as preocupações raciais como os saxônicos. Por isso "desde o primeiro momento, o colono traz para as suas carícias a índia, como, depois, traz a negra" (BOMFIM, 1997, p. 117), constituindo-se uma prole que se educa num entre lugar, entre dois mundos de tradições distintas, dando origem a uma tradição nova e vigorosa que, para Bomfim, já seria brasileira, autóctone, mestiça e vinculada à posse e à ocupação do território.

Para ampliarmos nossa compreensão sobre esta temática, torna-se importante retomarmos o debate entre Bomfim e Oliveira Viana no qual o autor sergipano critica a adoção de um racismo sociológico e a defesa do branqueamento por parte de Viana como alternativa histórica para nação. Segundo Bomfim:

Um alemão, em critério de verdadeira ciência, Martius, contemplando a história do Brasil no valor das raças formadoras, não achou nenhuma razão para duvidar da nossa capacidade de progresso. No entanto, compreende-se que tais europeus, a poucos erguidos para a alta cultura, por orgulho, ou outros motivos mais baixos, falseiam os fatos, e violentam a lógica, remoendo conceito donde resulte a decantada superioridade do 
dolicocefalismo louro; mas dá para desnortear o ver-se o governo de uma nação absolutamente misturada em raças, levantar essa mesma teoria, e esperar de uma impossível depuração de sangue, a graduação dos destinos nacionais. Para a etnologia do Sr. Viana, são os negros os mais irremissivelmente inferiores (BOMFIM, 1997, p. 94).

Como podemos perceber na citação anterior, Bomfim entende a sociologia cientificista de Oliveira Viana como uma falsa ciência e tudo o que essa falsa ciência disse e continuava a dizer contra a massa brasileira - por ser produto de cruzamentos - já vinha sendo desautorizado pela verdadeira ciência da qual Bomfim busca fazer parte. Por isso ele entende a nação brasileira como produto de cruzamentos raciais e culturais num grau tão elevado e por tanto tempo que seria para ele uma insensatez qualquer defesa do branqueamento ou pureza racial; para o intelectual sergipano, propor isso seria negar a essência da formação brasileira, ignorando o Brasil real em detrimento de uma quimera racial de valor duvidoso, pois "no Brasil tradicional, efetivo e real, desde os seus primeiros anos até hoje, o povo, a realidade mesma da nação, é mistura" (BOMFIM, 1997, p. 183) não sendo possível identificar um perfil que fugisse dessa realidade; por isso, segundo ele, propor ideias de pureza ou arianismo era nada mais que um simples "arremedo de ciência".

Seu texto analisa a questão da mestiçagem de uma forma que transcende a perspectiva de raça, sinalizando que o encontro entre tradições distintas era essencial para o desenvolvimento de novas sociedades, contribuindo diretamente para o desenvolvimento de novos tipos sociais. Para Bomfim (1997), o brasileiro não era um português emigrado, pois o contato com a terra, as energias emocionais despendidas nas lutas pela defesa do território, os constantes cruzamentos e o caldeamento de tradições formaram um novo sujeito histórico, que carregava consigo os aspectos positivos das tradições formadoras e, ao mesmo tempo, enunciava a gênese de uma nova tradição, que deveria ser entendida e defendida como a maior riqueza nacional.

Bomfim (1997) aponta que as teorias raciais que davam ênfase aos aspectos negativos da mestiçagem eram teorias colocadas a serviço da inferiorização do povo brasileiro, simples "preconceitos alçados à sociologia" e a pretensas políticas oficiais de governo. O Brasil na América é, pois, uma obra para contrapor-se a Populações meridionais do Brasil (1920), visando rebater as teses arianistas de Viana. Criticando a influência de Gustave Le Bon e Lapouge sobre os pensadores latino-americanos, Bomfim afirma:

Foi, sem dúvida, essa erudição que levou o etnólogo oficial a desbancar índios e negros. Ele está na fase de crença em dolicocefalia e arianismo, a ponto de supor que eram assim, louros e cumpridos de cabeça, os colonos 
que fizeram o Brasil: "um homem superior deve ser sempre grande, dolicocéfalo e louro... Na obra do descobrimento são os dolicocéfalos que tomam a dianteira...". E, daí, sem maiores hesitações, está o Sr. Viana a afirmar que todos esses fundadores de grandes famílias, no Sul e no Norte, eram, se não puros, ao menos muito alourados e alongados de crânio (BOMFIM, 1997 p.193-194).

Rebatendo as ideias de Oliveira Viana, Bomfim pretendia afirmar positivamente as origens da sociedade brasileira como uma nação mestiça, visto que, segundo ele, a mestiçagem fora a tônica de nosso passado e permanecia sendo em seu presente. Por isso, para o autor, pretender que dessas origens possa sair outra coisa que não uma população amplamente mestiça é pretender o impossível. Bomfim coloca a mestiçagem entre portugueses e índios como um fator primordial para a conquista do território, visto que, em sua perspectiva, foi graças a ela que as novas populações puderam adaptar-se ao clima e ao território. Citando Robert Southey, Bomfim afirma que "índios, negros e brancos se irão fundindo gradualmente, num só povo, que terá por herança uma das mais formosas porções do globo" (BOMFIM, 1997 p. 195), sinalizando a possibilidade de um futuro glorioso para a nação que se formava da mescla das três raças formadoras.

Ao refletir sobre a importância dos cruzamentos entre as três raças na formação brasileira, Bomfim (1997) chama a atenção para a necessidade de reconhecer e aceitar a miscigenação como um aspecto fundamental para o entendimento da sociedade brasileira:

Conheçamo-nos, e chegaremos à convicção de que somos um povo cruzado, e que povos cruzados serão sempre aquilo em que se fizeram: expressão de misturas combinadas. Poderão unificar-se; hão de unificar-se, em tipos definidos e estáveis. E esta certeza nos basta. Aceitemos o destino em que nos formamos; tenhamos a hombridade de ser o que somos, e façamos o dever em esforços, para que esse povo misturado venha a ser uma nação de civilização realmente humana, aproveitando todas as possibilidades de espírito e de coração, como as encontramos, na herança das raças donde viemos (BOMFIM, 1997 p. 195).

Da mesma forma, assim como havia feito em América Latina, Bomfim valoriza os cruzamentos e desqualifica o valor científico das teorias raciais postulando que o valor das raças era apenas valor de cultura: "há diferenças de tradições, há variedade de civilização, há maior ou menos aproveitamento das qualidades naturais, há direções e perspectivas históricas, mas diferença essencial de valor psíquico, não” (BOMFIM, 1997 p. 196). Dessa forma, Bomfim posiciona-se criticamente em relação ao arianismo de Viana como um sofisma colocado a serviço da desvalorização e inferiorização do povo brasileiro. 
De todos os ensaios históricos de Bomfim, O Brasil na América é possivelmente o menos comentado por seus intérpretes. Suas teses a respeito da formação da identidade brasileira como corolário das lutas de conquista e dos processos de ocupação do território ficam eclipsadas pelas suas críticas às teorias raciais, que são o eixo norteador de seus estudos históricos desde 1897. Contudo, uma questão sempre lembrada por seus intérpretes quando se debruçam sobre a respectiva obra é a pouca representatividade dada aos negros no processo de formação da sociedade brasileira, pois, em mais de cem páginas dedicadas ao estudo da importância dos cruzamentos na formação brasileira, apenas sete são dedicadas ao estudo sistemático da importância e das contribuições dos negros para a cultura nacional.

Alguns autores, de forma apressada, atribuíram esse fato como resquícios de uma tendência racista que teria se manifestado no texto do autor. Efetivamente, não compartilhamos dessa interpretação, pois a ênfase do texto é pensar o momento mítico de fundação nacional. Como Bomfim representa de forma bastante idealizada esse momento de fundação mítica da nação, no contato entre os primeiros colonizadores e os indígenas nos séculos XVI e XVII, o negro não estava presente nesse primeiro impulso de formação nacional, mas a sua contribuição é incorporada por meio da miscigenação, oferecendo uma importância renovadora para a tradição que estava se formando.

Na obra As identidades do Brasil: de Calmon a Bomfim, José Carlos Reis (2006) refere-se ao projeto intelectual de Bomfim como "um otimismo revolucionário ingênuo" (REIS, 2006, p. 183). Essa obra apresenta uma narrativa em relação a alguns aspectos da obra do sergipano, mas deixa muito a desejar pela superficialidade com que algumas temáticas da obra de Bomfim são abordadas. Esse é um problema comum em trabalhos cuja proposta analítica é refletir sobre autores diferentes, situados em tempos e espaços distintos. Tal visão sintética e interessada em levantar polêmicas levou Reis (2006) a produzir alguns adjetivos que descrevem o sergipano como "racista", "fascista", "integralista" e numa das mais brandas adjetivações “ingênuo".

Essas adjetivações não condizem com a realidade, nem com a amplitude da obra e o perfil do intelectual sergipano. Basta fazer uma leitura da biografia sociológica produzida por Ronaldo Conde Aguiar (1999), que seremos convencidos de que não dá para compartilhar com a "teoria da ingenuidade" produzida pelo autor de Identidades do Brasil. Bomfim foi um intelectual crítico de sua época, que elaborou a sua obra em desacordo com os padrões de verdade dominantes em seu tempo e que, talvez por isso, tenha sido capaz de captar em seu ensaísmo histórico anseios que outros intelectuais presos aos padrões de verdade e aos critérios de validade de sua época não conseguiram perceber. Ele produziu uma consciência 
possível de seu tempo, tendo como referência uma preocupação dissonante em relação a seus pares intelectuais.

Segundo Aguiar (1999), Bomfim acreditava na importância das utopias, mas definiase como um utopista e não como um utópico: “o utópico não tem os pés nem as mãos no mundo real. O utopista quer mudar o mundo através da luta consciente e do trabalho" (AGUIAR, 1999, p. 28). Do ponto de vista histórico, não é produtivo entender a obra de Bomfim, ou de qualquer outro pensador, como ingênua, pois corremos o risco de criar um clichê historiográfico que pouco contribui para o entendimento do autor ou da obra. Nesse sentido, Bomfim foi um homem de seu tempo, que se diferenciou por sua sensibilidade de pensar uma história do Brasil, protagonizada por negros, índios, pobres, sertanejos, trabalhadores e operários, com claros matizes democráticos e de inspiração popular, opondose aos interesses dominantes em sua época, que pensava o Brasil olhando da parte de cima da pirâmide social.

\section{REFERÊNCIAS BIBLIOGRÁFICAS}

AGUIAR, R. C. O rebelde esquecido: tempo vida e obra de Manoel Bomfim. Rio de Janeiro: Topbooks, 1999.

BOMFIM, M. A América Latina: males de origem. 3. ed. Rio de Janeiro: Topbooks, 1993. O Brasil na América: caracterização da formação brasileira. 2. ed. Rio de Janeiro: Topbooks, 1997.

COSTA, J. C. de C. Nação, raça e miscigenação no Brasil moderno: uma análise hermenêutica dos ensaístas da formação da nacionalidade brasileira, 1888-1928. Recife, 2003. 311f. Tese (Doutorado em Sociologia), Programa de Pós-Graduação em Sociologia.

FILHO, A. A. Manoel Bomfim: combate ao racismo, educação popular e democracia radical. São Paulo: Expressão Popular, 2008.

JANCSÓ, I. Brasil: formação do Estado e da Nação. São Paulo: HUCITEC, 2003.

JUNIOR, V. D. S. A trama das ideias: intelectuais, ensaios e construção de identidades na América Latina (1898-1914). 2013. 274f Tese (Doutorado em História Social) - Programa de Pós-Graduação em História Social, Universidade de São Paulo, São Paulo, 2013.

NEVES, C. R. das. O projeto de identidade latino-americana de Manoel Bomfim na obra América Latina Males de Origem (1905). Goiânia: UFG, 2010. 
OLIVA, T. A. de. O pensamento geográfico em Manoel Bomfim. 1998. 169f. Tese (Doutorado em Geografia) - Programa de Pós-Graduação em Geografia, Universidade Estadual Paulista (Unesp), Rio Claro-SP, 1998.

OLIVEIRA, L. L. A questão nacional na Primeira República. São Paulo: Brasiliense; Brasilia: CNPq, 1990.

REIS, J. C. As identidades do Brasil II: de Calmon a Bomfim. 2. ed. Rio de Janeiro: FGV, 2006.

RIBEIRO, D. Manoel Bomfim antropólogo In: BOMFIM, Manoel. América Latina: males de origem. Rio de Janeiro: Topbooks, 1993.

PRADO, M. L. C. Repensando a história comparada da América Latina. Revista de História, n. 153, 2005.

SILVA, A. A. Autoritarismo ou revolução: identidade nacional brasileira e democracia nas interpretações históricas de Oliveira Viana e Manoel Bomfim. 2009. 209f. Dissertação (Mestrado em História) - Universidade Federal de Minas Gerais (UFMG), Belo Horizonte, 2009.

SUSSEKIND, F.; VENTURA, R. História e dependência: cultura e sociedade em Manoel Bomfim. São Paulo: Moderna, 1984.

VIANA, O. Populações meridionais do Brasil. v. 1, Rio de Janeiro: Paz e Terra, 1973.

ARTIGO ENVIADO EM: 02/08/2016

ARTIGO ACEITO PARA PUBLICAÇÃO EM: 26/12/2016 